\title{
Simultaneous Triple Series Equations Involving Konhauser Biorthogonal Polynomials
}

\author{
P.K. Mathur, \\ Department of Mathematics, Saifia College, Bhopal, (M.P.)
}

\begin{abstract}
Biorthogonal polynomials are of great interest for Physicists.Spencer and Fano ${ }^{[9]}$ used the biorthogonal polynomials (for the case $k=2$ ) in carrying out calculations involving penetration of gamma rays through matter.In the present paper an exact solution of simultaneous triple series equations involving Konhauser-biorthogonal polynomials of first kind of different indices is obtained by multiplying factor technique due to Noble. ${ }^{[4]}$ This technique has been modified by Thakare ${ }^{[10,11]}$ to solve dual series equations involving orthogonal polynomials which led to disprove a possible conjecture of Askey ${ }^{[l]}$ that a dual series equation involving Jacobi polynomials of different indices can not be solved. In this paper the solution of simultaneous triple series equations involving generalized Laguerre polynomials also have been discussed as a charmfull particular case.

Key Words: 45F 10 Simultaneous Triple Series Equations, 33C45 Konhasure bi-orthogonal polynomials, Laguerre polynomials,42C O5 Orthogonal Functions and polynomials, General Theory, 33D45 Basic Orthogonal polynomials, 26433 Fractional derivatives and integrals.
\end{abstract}

\section{Introduction}

Konhauser ${ }^{[3]}$ introduced a pair of sets of bi-orthogonal polynomials $Z_{n}^{\alpha}(x ; k)$ and $Y_{n}^{\alpha}(x ; k)$ with respect to the weight function $x^{\alpha} \exp (-x)$ over the interval $(0, \infty)$ based on the study of Preiser ${ }^{[7]}$. In fact Konhauser defined

$\mathrm{Z}_{\mathrm{n}}^{\alpha}(\mathrm{x} ; \mathrm{k})=\frac{\Gamma(\mathrm{kn}+\alpha+1)}{\mathrm{n} !} \sum_{\mathrm{j}=0}^{\mathrm{n}}(-1)^{\mathrm{j}}\left(\begin{array}{l}\mathrm{n} \\ \mathrm{j}\end{array}\right) \frac{\mathrm{x}^{\mathrm{kj}}}{\Gamma(\mathrm{kj}+\alpha+1)}$

and

$$
\mathrm{Y}_{\mathrm{n}}^{\alpha}(\mathrm{x} ; \mathrm{k})=\frac{1}{\mathrm{n} !} \sum_{\mathrm{p}=0}^{\mathrm{n}} \frac{\mathrm{x}^{\mathrm{p}}}{\mathrm{n} !} \sum_{\mathrm{q}=0}^{\mathrm{p}}(-1)^{\mathrm{q}}\left(\begin{array}{l}
\mathrm{p} \\
\mathrm{q}
\end{array}\right)\left[\frac{\mathrm{q}+\alpha+1}{\mathrm{k}}\right] \mathrm{n}
$$

$\mathrm{Z}_{\mathrm{n}}^{\alpha}(\mathrm{x} ; \mathrm{k})$ is called Konhauser-biorthogonal set of the first kind and $\mathrm{Y}_{\mathrm{n}}^{\alpha}(\mathrm{x} ; \mathrm{k})$ the Konhauser-biorthogonal set of the second kind. For $\mathrm{k}=1$, both the polynomials reduce to the generalized Laguerre polynomials $\mathrm{L}_{\mathrm{n}}^{\alpha}(\mathrm{x})$.

In the present paper we shall solve simultaneous triple series equations of the form

$$
\begin{aligned}
& \sum_{n=0}^{\infty} \sum_{j=1}^{s} a_{j} \frac{A_{n j Z} \underset{n i+p}{\alpha}(x ; k)}{\Gamma(\alpha+k n i+p+1)}=f_{i}(x), \quad 0 \leq x<a \\
& \sum_{\mathrm{n}=0}^{\infty} \sum_{\mathrm{j}=1}^{\mathrm{s}} \mathrm{b}_{\mathrm{j}} \frac{\mathrm{A}_{\mathrm{n} \mathrm{Z}_{\mathrm{ni}}}^{\beta+\mathrm{p}}(\mathrm{x} ; \mathrm{k})}{\Gamma(\delta+\beta+\mathrm{kni}+\mathrm{p})}=\mathrm{gi}_{\mathrm{i}}(\mathrm{x}), \quad \mathrm{a}<x<b \\
& \sum_{n=0}^{\infty} \sum_{j=1}^{s} c_{i j} \frac{A_{n j Z_{n i}+p}(x ; k)}{\Gamma(\delta+\beta+k n i+p)}=h_{i}(x), \quad b<x<\infty
\end{aligned}
$$

Where $\mathrm{Z}_{\mathrm{n}}^{\alpha}(\mathrm{x} ; \mathrm{k})$ is the Konhauser-biorthogonal polynomial, $\mathrm{f}_{\mathrm{i}}(\mathrm{x}), \mathrm{g}_{\mathrm{i}}(\mathrm{x})$, and

$\mathrm{h}_{\mathrm{i}}(\mathrm{x})$ are prescribed functions, $\mathrm{a}_{\mathrm{i}}, \mathrm{b}_{\mathrm{i}_{\mathrm{j}}}$ and $\mathrm{c}_{\mathrm{j}}$ are known constants for $\mathrm{i}=1,2, \ldots \ldots \ldots, \mathrm{s}$ and $\mathrm{j}=1,2, \ldots \ldots \ldots \ldots, \mathrm{s} . \delta+\beta+\mathrm{m}>\alpha+1>0$ and 
$\sigma+1>\delta+\beta>0$, $\mathrm{m}$ being some positive integer and $\mathrm{p}$ is a non-negative integer. $\mathrm{A}_{\mathrm{n}^{\prime} \mathrm{s}}$ are the unknown constants for $\mathrm{j}=1,2, \ldots \ldots \ldots \ldots . ., \mathrm{s}$. in the series equations which are to be determine.

\section{Results Used In The Sequel}

During the course of analysis the following results shall be needed:

(i) Biorthogonal relation was given by Konhauser ${ }^{[3]}$ as follows:

$$
\begin{gathered}
\int_{0}^{\infty} \mathrm{e}^{-\mathrm{x}} \mathrm{x}^{\alpha} \mathrm{z}_{\mathrm{n}}^{\alpha}(\mathrm{x} ; \mathrm{k}) \mathrm{Y}_{\mathrm{m}}^{\alpha}(\mathrm{x} ; \mathrm{k}) \mathrm{dx}=\frac{\Gamma(\mathrm{kn}+\alpha+1)}{\mathrm{n} !} \delta_{\mathrm{m}}^{\mathrm{n}} \\
\text { where } \delta_{\mathrm{m}}^{\mathrm{n}} \text { is Kranecker's delta. }
\end{gathered}
$$

(ii) Prabhakar ${ }^{[6]}$ introduced the following $\mathrm{m}^{\text {th }}$ differential formula in the form

$$
\frac{\mathrm{d}^{\mathrm{m}}}{\mathrm{dx}}\left[\mathrm{x}^{\alpha+\mathrm{m}_{\mathrm{z}}} \mathrm{Z}_{\mathrm{n}}^{\alpha+\mathrm{m}}(\mathrm{x} ; \mathrm{k})\right]=\frac{\Gamma(\mathrm{kn}+\alpha+\mathrm{m}+1) \mathrm{x}^{\alpha} \mathrm{z}_{\mathrm{n}}^{\alpha}(\mathrm{x} ; \mathrm{k})}{\Gamma(\mathrm{kn}+\alpha+1)}
$$

With $\alpha>-1$.

(iii) Prabhakar ${ }^{[6]}$ introduced the following fractional integrals, the first being the Riemann- Liouville fractional integral:

$$
\begin{aligned}
\int_{0}^{\xi}(\xi-x)^{\beta-1} x^{\alpha} z_{n}^{\alpha}(x ; k) d x \\
\quad=\frac{\Gamma(k n+\alpha+1) \Gamma(\beta)}{\Gamma(\mathrm{kn}+\alpha+\beta+1)} \xi^{\alpha+\beta} Z_{n}^{\alpha+\beta}(\xi ; k)
\end{aligned}
$$

when $\beta>0, \alpha+\beta+1>0$

and the second, the Weyl fractional integral

$\left.\int_{\xi}^{\infty} \mathrm{e}^{-\mathrm{x}}(\mathrm{x}-\xi)\right)^{\beta-1} \mathrm{Z}_{\mathrm{n}}^{\alpha}(\mathrm{x} ; \mathrm{k}) \mathrm{dx}=\Gamma(\beta) \mathrm{e}^{-\xi_{\mathrm{Z}}}{ }_{\mathrm{n}}^{\alpha-\beta}(\xi ; \mathrm{k}) \quad$ [2.4]

where $\alpha+1>\beta>0$

\section{The Solution Of Triple Series Equations :}

Multiplying both the sides of the equation [1.1] by $x^{\alpha}(\xi-x)-\alpha+\beta+\delta+m-2$ and

Integrating with respect to $\mathrm{x}$ over $(0, \xi)$ and further using first fractional integral formula [2.3]

$$
\text { we get } \begin{aligned}
\sum_{n=0}^{\infty} \sum_{j=1}^{s} a_{i_{j}} \frac{A_{n_{j} \Gamma(-\alpha+\beta+\delta+m-1)}}{\Gamma(k n i+p+\beta+\delta+m)} \xi^{\beta+\delta+m-1} z^{\beta+\delta+m-1}{ }_{(\xi ; k)} & n i+p \\
= & \int_{0}^{\xi} x^{\alpha}(\xi-x)^{-\alpha+\beta+\delta+m-2} f_{i}(x) d x
\end{aligned}
$$

From the relation [3.1], we have

$$
\begin{aligned}
& \sum_{n=0}^{\infty} \sum_{j=1}^{s} a_{i j} \frac{A_{n j Z^{j}}^{\beta+\delta+m-1}(\xi ; k)}{\Gamma(k n i+p+\beta+\delta+m)} \\
& =\frac{\xi^{-\beta-\delta-m+1}}{\Gamma(-\alpha+\beta+\delta+m-1)} \int_{0}^{\xi} x^{\alpha}(\xi-x)^{-\alpha+\beta+\delta+m-2} \mathrm{f}_{\mathrm{i}}(\mathrm{x}) \mathrm{dx}
\end{aligned}
$$

with $0<\mathrm{x}<\xi$ and $\beta+\delta+\mathrm{m}>\alpha+1>0$

Now multiplying both sides of equation [3.2] by $\xi^{\beta+\delta}+\mathrm{m}-1$ and differentiating both sides ' $\mathrm{m}$ ' times with respect to $\xi$ and using the derivative formula [2.2] we get

$$
\sum_{\mathrm{n}=0}^{\infty} \sum_{\mathrm{j}=1}^{\mathrm{s}} \mathrm{b}_{\mathrm{j}} \frac{\mathrm{A}_{\mathrm{njZ}} \mathrm{ni}_{\mathrm{ni}+\mathrm{p}}^{\beta+\delta-1}(\xi \mathrm{k})}{\Gamma(\mathrm{kni}+\mathrm{p}+\beta+\delta)}=\sum_{\mathrm{j}=1}^{\mathrm{s}} \mathrm{d}_{\mathrm{j}} \frac{\xi^{-\beta-\delta+1}}{\Gamma(-\alpha+\beta+\delta+\mathrm{m}-1)} \mathrm{F}_{\mathrm{i}}(\xi), 0<\xi<a
$$

where $F_{i}(\xi)=\frac{d^{m}}{d x} \int_{0}^{\xi} x^{\alpha}(\xi-x)^{-\alpha+\beta+\delta+m-2} f_{i}(x) d x$,

$\mathrm{i}=1,2, \ldots$

and $\mathrm{d}_{\mathrm{ij}}$ are the elements of the matrix $\left[\mathrm{b}_{\mathrm{ij}}\right]\left[\mathrm{a}_{\mathrm{i}}\right]^{-1}$.

Next we multiply both the sides of the equation [1.3] by $\mathrm{e}^{-\mathrm{x}}(\mathrm{x}-\xi)^{\sigma-\delta-\beta}$ and integrate with respect to $\mathrm{x}$ over $(\xi, \infty)$ and using second fractional integral formula [2.4], we get

$\sum_{\mathrm{n}=0}^{\infty} \sum_{\mathrm{j}=1}^{\mathrm{s}} \mathrm{c}_{\mathrm{j}} \frac{\mathrm{A}_{\mathrm{j}} \Gamma(\sigma-\delta-\beta+1)}{\Gamma(\mathrm{kni}+\mathrm{p}+\delta+\beta)} \mathrm{e}^{-\xi_{\mathrm{Z}}}{ }_{\mathrm{ni}+\mathrm{p}}+\delta{ }_{(\xi ; \mathrm{k})}=\int_{\xi}^{\infty} \mathrm{e}^{-\mathrm{x}}(\mathrm{x}-\xi)^{\sigma-\delta}-\beta \mathrm{h}_{\mathrm{i}}(\mathrm{x}) \mathrm{dx}$

which can be written as 


$$
\sum_{n=0}^{\infty} \sum_{j=1}^{s} \mathrm{c}_{\mathrm{j}} \frac{\mathrm{A}_{\mathrm{j}} \mathrm{Z}_{\mathrm{ni}+\mathrm{p}}^{\beta+\delta-1}(\xi ; \mathrm{k})}{\Gamma(\mathrm{kni}+\mathrm{p}+\delta+\beta)}=\frac{\mathrm{e}^{\xi}}{\Gamma(\sigma-\delta-\beta+1)} \int_{\xi}^{\infty} \mathrm{e}^{-\mathrm{x}}(\mathrm{x}-\xi)^{\sigma-\delta}-\beta \mathrm{h}_{\mathrm{i}}(\mathrm{x}) \mathrm{dx}
$$

where $\xi<x<\infty, \sigma+1>\delta+\beta>0$.

From equation [3.6], we get

$$
\begin{aligned}
& \sum_{\mathrm{n}=0}^{\infty} \sum_{\mathrm{j}=1}^{\mathrm{s}} \mathrm{b}_{\mathrm{j}} \frac{\mathrm{A}_{\mathrm{nj}} \mathrm{z}_{\mathrm{ni}+\mathrm{p}}^{\beta+\delta-1}(\xi ; \mathrm{k})}{\Gamma(\mathrm{kni}+\mathrm{p}+\delta+\beta)}=\sum_{\mathrm{j}=1}^{\mathrm{s}} \mathrm{e}_{\mathrm{j}} \frac{\mathrm{e}^{\xi}}{\Gamma(\sigma-\delta-\beta+1)} \mathrm{H}_{\mathrm{i}}(\xi), \mathrm{b}<\xi<\infty . \\
& \text { where } \mathrm{H}_{\mathrm{i}}(\xi)=\int_{\xi}^{\infty} \mathrm{e}^{-\mathrm{x}}(\mathrm{x}-\xi)^{\sigma-\delta} \beta_{\mathrm{h}_{\mathrm{i}}(\mathrm{x}) \mathrm{dx}, \mathrm{i}=1,2, \ldots \ldots \ldots \ldots \ldots \ldots \ldots, \mathrm{s} .}
\end{aligned}
$$

and $\mathrm{e}_{\mathrm{j}}$ are the elements of the matrix $\left[\mathrm{b}_{\mathrm{j}}\right]\left[\mathrm{c}_{\mathrm{j}}\right]^{-1}$.

Now left hand sides of the equations [3.3], [1.2] and [3.7] are identical. Applying the biorthogonal relation [2.1] of Konhauser polynomials, we get the solution of the simultaneous triple series equations in the form

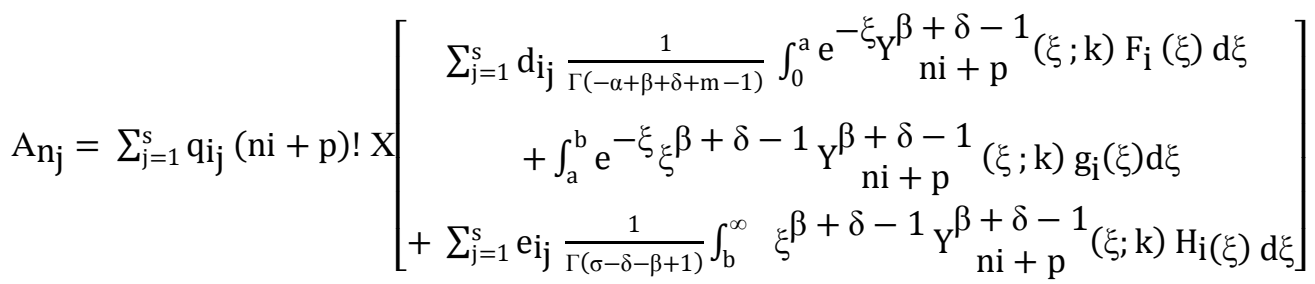

where $\mathrm{q}_{\mathrm{i}}$ are the elements of the matrix $\left[\mathrm{b}_{\mathrm{j}}\right]^{-1}$ and $\mathrm{n}=0,1,2, \ldots \ldots$ and $\mathrm{j}=1,2, \ldots \ldots ., \mathrm{s}$ and $\mathrm{F}_{\mathrm{i}}(\xi), \mathrm{H}_{\mathrm{i}}(\xi)$ are defined by [3.4] and [3.8] respectively.

\section{Particular Case}

It is very interesting for us if we put $\mathrm{k}=1$ in equations [1.1], [1.2] and [1.3] then Konhauser polynomials involved in these equations are reduced to generalized Laguerre polynomials and we receive the following Simultaneous triple series equations involving generalized Laguerre polynomials

$$
\begin{aligned}
& \sum_{n=0}^{\infty} \sum_{j=1}^{s} a_{i j} \frac{A_{n_{j}} L_{n i+p}^{(\alpha)}(x)}{\Gamma(\alpha+k n i+p+1)}=f_{i}(x), \quad 0 \leq x<a
\end{aligned}
$$

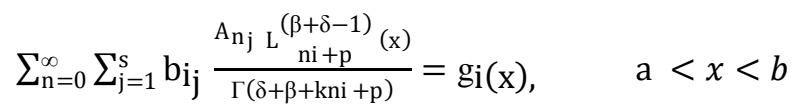

$$
\begin{aligned}
& \sum_{n=0}^{\infty} \sum_{j=1}^{s} c_{i j} \frac{A_{n j} L_{n i+p}(\sigma)}{\Gamma(\delta+\beta+k n i+p)}=h_{i}(x), \quad b<x<\infty
\end{aligned}
$$

with the solution in the form

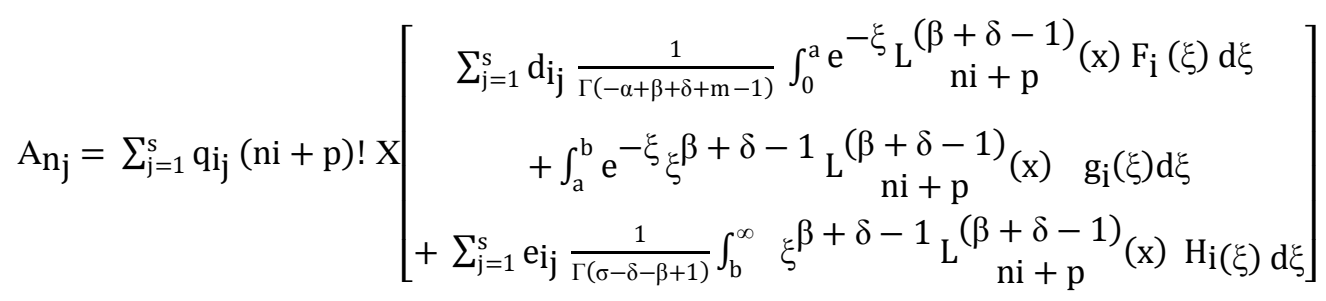

where $\mathrm{q}_{\mathrm{i}}$ are the elements of the matrix $\left[\mathrm{b}_{\mathrm{i}}\right]^{-1}$ and $\mathrm{n}=0,1,2, \ldots \ldots$ and $\mathrm{j}=1,2, \ldots \ldots ., \mathrm{s}$ and $\mathrm{F}_{\mathrm{i}}(\xi), \mathrm{H}_{\mathrm{i}}(\xi)$ are defined by [3.4] and [3.8] respectively when $\mathrm{k}=1$.

\section{REFERENCES}

[1]. Askey, Richard: Dual equations and classical orthogonal polynomials, J. Math. Anal. Applic., 24, pp. 677- 685, (1968)

[2]. Konhasure, J.D.E. : Some properties of biorthogonal polynomials, Ibid, 11, pp.242- 260, (1965).

[3]. Konhasure, J.D.E. : Biorthogonal polynomials suggested by the Laguerre polynomials, Pacific J. Math. , 21, pp. 303- 314, (1967)

[4]. Noble, B.: Some dual series equations involving Jacobi polynomials, Proc. Camb.

[5]. phil. Soc., 59, pp. 363-372, (1963). 
[6]. Patil, K.R. and Thakare, N.K. : Certain dual series equations involving the Konhasure orthogonal polynomials, J. Math. Phys. , 18, pp. 1724- 1726, (1977).

[7]. Prabhakar, T.R. : On a set of polynomials suggested by Laguerre polynomials, Pacific J. Math. , 35, pp. 213- 219, (1970).

[8]. Preiser, S. : An investigation of biorthogonal polynomials derivable from ordinary differential equation of the third order, J. Math. Anal. Applic., 4, pp. 38- 64, (1962).

[9]. Rainville, E.D. : Special Function, Macmillan and Co., New York, (1967).

[10]. Spencer, L. and Fano, U. : Penetration and diffusion of X-rays, Calculation of spatial distributions by polynomial expansion, J. Res. natn. Bur. Std. , 46, pp.446- 461, (1951).

[11]. Thakare, N.K. : Remarks on dual series equations involving orthogonal polynomials, J. Shivaji Univ., 5, pp. 67- 72, (1972).

[12]. Thakare, N.K. : Dual series equations involving Jacobi polynomials, Zeitschrift fur Aug. Math. Mech. 54, pp. 283- 284, (1974). 